\title{
Renal actions of angiotensin-(1-7)
}

\section{A.C. Simões-e-Silva, \\ N.C.V. Baracho, \\ K.T. Passaglio and \\ R.A.S. Santos}

\author{
Laboratório de Hipertensão, Departamento de Fisiologia e Biofísica, \\ Instituto de Ciências Biológicas, Universidade Federal de Minas Gerais, \\ 31270-901 Belo Horizonte, MG, Brasil
}

\begin{abstract}
Correspondence
R.A.S. Santos

Departamento de Fisiologia e

Biofísica

ICB-UFMG

Av. Antonio Carlos, 6627

31270-901 Belo Horizonte, MG

Brasil

Fax: 55 (031) 441-0835

Presented at the International Symposium "Neuroendocrine

Control of Body Fluid Homeostasis",

Ribeirão Preto, SP, Brasil,

August 17-20, 1996.

Research supported by CNPq, CAPES and FAPEMIG.
\end{abstract}

Received November 29, 1996 Accepted December 17, 1996 . . . . . . . . . . .

\begin{abstract}
The heptapeptide angiotensin-(1-7) is considered to be a biologically active endproduct of the renin-angiotensin system. This angiotensin, which is devoid of the most known actions of angiotensin II such as induction of drinking behavior and vasoconstriction, has several selective effects in the brain and periphery. In the present article we briefly review recent evidence for a physiological role of angiotensin(1-7) in the control of hydroelectrolyte balance.
\end{abstract}

Key words

- Angiotensin antagonists

- Angiotensin II

- Hydroelectrolyte balance

- Renin-angiotensin system

- Kidney

- Water transport

\section{Introduction}

The classical view that angiotensin II (Ang II) mediates all actions of the renin-angiotensin system (RAS) has been modified in the past few years by the demonstration that other angiotensin peptides (Figure 1), especially angiotensin-(1-7) (Ang-(1-7)) may selectively mediate actions of the RAS (1-3). Ang-(1-7) can be formed by an angiotensin converting enzyme (ACE)-independent pathway (4), and exerts important biological effects. In vitro this peptide is a potent vasopressin secretagogue (5) and possesses a potent prostaglandin-releasing activity in several cell lines $(6,7)$. Microinjection of this angiotensin into the dorsomedial or ventrolateral medulla produces significant changes in mean arterial pressure and heart rate, comparable to those produced by Ang II (8-11). Furthermore, intracerebroventricular infusion of Ang-(1-7) in rats increased baroreceptor reflex sensitivity, an effect that was opposite to that observed with Ang II infusion (12). Other findings have indicated that Ang-(1-7) can act as an osmoregulatory peptide. Immunohistochemistry demonstrated that this peptide is present in brain areas related to the control of hydromineral balance (13). Addi- tional studies in our laboratory have demonstrated that Ang-(1-7) has a potent antidiuretic effect in water-loaded rats (14) and that its plasma concentration is increased by hemorrhage or by maneuvers known to increase plasma osmolality such as water deprivation and salt load (15). A natriuretic effect of Ang-(1-7) in isolated rat kidneys (16) or in denervated rat kidneys in vivo (17) has also been described. Ongoing studies strongly suggest that these biological effects are mediated by specific receptors $(10,11)$. These data indicate that Ang-(1-7) could be involved in the mediation of important central and peripheral actions of the RAS.

As documented above, in the past few years a large body of evidence has been accumulated suggesting a role for Ang-(1-7) in the control of hydroelectrolyte balance. However, due to several factors discussed below there is no consensus regarding the major action of Ang-(1-7) in the kidney. Several studies suggest a major role of Ang(1-7) as a natriuretic peptide (16-18) while other studies, including ours, point to a major role of this angiotensin in water transport (19-22). It should be pointed out, however, that, even when apparently contradictory, these studies clearly show that the renal ac- 
Figure 1 - Pathways of angiotensin processing.
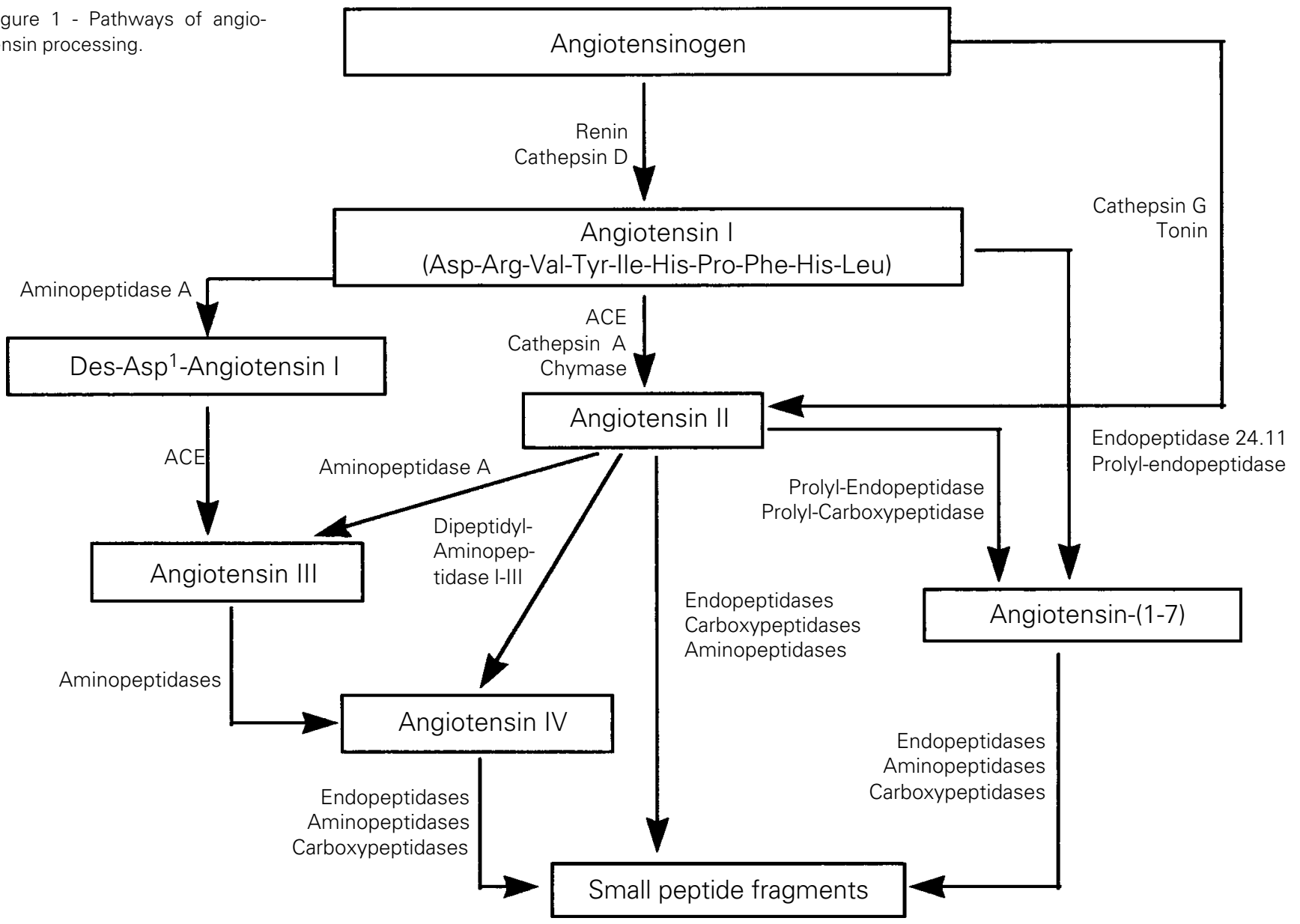

tions of Ang-(1-7) are very complex, apparently involving both the proximal and distal nephron as is also the case for Ang II.

In the present article we briefly review the main evidence for a physiological role of Ang-(1-7) in the control of hydroelectrolyte balance, especially that dealing with water and sodium transport in the kidney.

\section{Renin-angiotensin system and the kidney}

The association of the renin-angiotensin system with kidney function is one of the most established concepts in physiology. The importance of the most active peptide of the RAS, Ang II, in hydroelectrolyte balance and cardiovascular homeostasis is due to its wide spectrum of biological activity.
Ang II is a potent vasoconstrictor that increases peripheral vascular resistance and thus mean arterial pressure. In situations of extracellular fluid volume contraction, Ang II reduces renal sodium excretion via alterations in renal hemodynamics, direct enhancement of proximal tubule sodium bicarbonate reabsorption, and aldosterone-mediated increases in late distal tubule and cortical collecting duct reabsorption $(23,24)$. Ang II also increases thirst, salt appetite and intestinal sodium absorption, all of which increase the extracellular fluid volume. There is growing evidence, however, that besides Ang II the heptapeptide Ang-(1-7) also plays a physiological role in the control of hydroelectrolyte balance, mainly through its activity on the kidney $(14,16,17,22)$.

In the following sections, we first briefly 
summarize the renal actions of the RAS mediated by Ang II and then discuss a variety of experimental findings that point to an important role for Ang-(1-7) in modulating renal function.

\section{Renal actions of angiotensin II}

Ang II is one of the most powerful regulators of sodium excretion, operating through extrarenal mechanisms, such as the stimulation of aldosterone secretion, as well as intrarenal mechanisms (23). In the physiological concentration range, Ang II acts mainly as an antinatriuretic hormone by directly or indirectly producing changes in renal hemodynamics and in sodium reabsorption (25). Considerable evidence suggests that the intrarenal actions of Ang II are quantitatively more important than the extrarenal mechanisms in the normal day-today regulation of sodium and water excretion $(23,26)$.

The extrarenal actions of Ang II include stimulation of the sympathetic nervous system and aldosterone secretion (23). The antinatriuretic effect of Ang II could be mediated in part by increased renal sympathetic nerve activity that in turn could increase renal tubular sodium reabsorption directly or indirectly by causing renal vasoconstriction (27). The other well-known extrarenal mechanism by which Ang II controls sodium and water excretion is through its indirect renal effect mediated by aldosterone. Aldosterone biosynthesis and secretion are strongly influenced by Ang II, which acts directly on adrenal glomerulosa cells to stimulate both early and late steps in the steroid biosynthetic cascade (28).

Two intrarenal effects of Ang II that may contribute to fluid retention and that occur at very low concentrations include the constriction of efferent arterioles and increased sodium transport by the renal tubules. Ang II markedly raises efferent glomerular arteriolar resistance (29) and does not change afferent arteriolar resistance unless the renal perfusion pressure rises (29). The consequence of the disproportionate increase in efferent (over afferent) resistance is a marked increase in the mean transcapillary hydraulic pressure, which results in an increase in mean transcapillary ultrafiltration pressure. Thus, the Ang II-induced decrease in renal plasma flow is offset by the increase in mean transcapillary ultrafiltration pressure and this maintains the glomerular filtration rate (GFR) by increasing the filtration fraction. Besides its effect on efferent arteriolar resistance, Ang II has a marked influence on glomerular mesangial tone. Ang II promotes mesangial cell contraction and thus a decrease in the glomerular capillary ultrafiltration coefficient (Kf) $(30,31)$. The Kf-lowering effect of Ang II is attenuated by the stimulatory effect of Ang II on the production of vasodilatory prostaglandins (32). Thus, the final effect of Ang II is a stable GFR despite the changes in renal perfusion pressure.

The vasoconstrictor effect of Ang II on efferent arterioles causes changes in peritubular capillary dynamics that could increase renal tubular fluid reabsorption (33). The efferent arteriolar vasoconstriction would reduce the peritubular capillary hydrostatic pressure as well as increase peritubular capillary colloid osmotic pressure due to an increase in the filtration fraction. Both of these changes would tend to decrease renal interstitial fluid hydrostatic pressure and raise interstitial fluid colloid osmotic pressure, thereby increasing the driving force for fluid reabsorption $(26,34)$.

Another mechanism by which Ang IImediated changes in renal hemodynamics could increase tubular reabsorption is by decreasing renal medullary blood flow (35). The constriction of efferent arterioles of juxtaglomerular nephrons or a direct action on the vasa recta may lower renal medullary blood flow and increase medullary interstitial fluid osmolality. The increased osmolality could raise the urine-concentrating abil- 
Figure 2 - Effect of angiotensin(1-7) and vasopressin on water diuresis. Male Wistar rats $(280$ to $320 \mathrm{~g}$ ) were submitted to a water load $(5 \mathrm{ml} / 100 \mathrm{~g}$ body weight, gavage) and immediately housed in metabolic cages with no water or chow. Within 60 min of the water load the urinary volume was measured and the rats were immediately injected intraperitoneally with vehicle $(0.9 \% \mathrm{NaCl}, \mathrm{SAL}, 0.05$ $\mathrm{ml} / 100 \mathrm{~g}$ body weight, $\mathrm{N}=6$ ), Ang-(1-7) (44 pmol/100 g body weight, $\mathrm{N}=6)$, or AVP (20 pmol/ $100 \mathrm{~g}$ body weight, $\mathrm{N}=4$ ). Following injection, the animals were returned to the metabolic cages and diuresis was measured 30 and 60 min after completion of the treatment. Data are reported as mean \pm SEM and were analyzed by oneway ANOVA, followed by the Newman-Keuls test. ${ }^{*} \mathrm{P}<0.05$ compared to the vehicle-treated group.

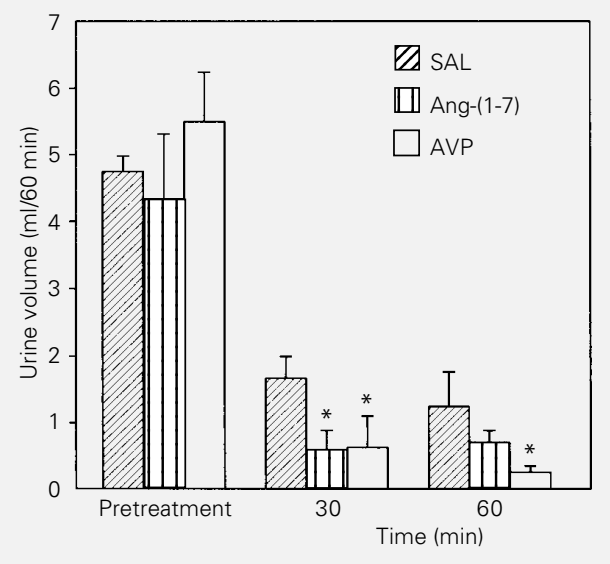

ity and tend to enhance passive sodium chloride reabsorption in the thin ascending limb of Henle's loop (36).

Micropuncture and microperfusion studies have shown that the effect of Ang II on proximal tubule sodium transport is bimodal (37). Ang II at concentrations of 1 to $100 \mathrm{pM}$ significantly stimulates proximal sodium reabsorption, whereas higher concentrations of 0.1 to $1 \mu \mathrm{M}$ inhibit transport (37). Various studies suggest that at physiological concentrations (1 to $100 \mathrm{pM}$ ) Ang II promotes sodium bicarbonate reabsorption by activation of $\mathrm{Na}^{+}-\mathrm{H}^{+}$exchange (38). Ang II also participates in the regulation of distal nephron acidification by stimulating the $\mathrm{Na}^{+}-\mathrm{H}^{+}$ exchange in early and late distal segments via activation of $\mathrm{AT}_{1}$ receptors, as well as vacuolar $\mathrm{H}^{+}$-ATPase in the late distal segment (39).

In contrast to its antinatriuretic actions, Ang II produces natriuresis when infused at supraphysiological concentrations that increase mean arterial pressure (25). This natriuretic effect of Ang II is mainly due to an increase in renal perfusion pressure and, additionally, to a direct inhibitory action on proximal tubular reabsorption. This effect, called pressure natriuresis, is thought to involve changes in peritubular Starling forces or interstitial pressures increasing back-leakage of fluid into the tubule lumen (25). Ang II-associated pressure natriuresis appears to serve as a negative feedback system on sodium retention produced by Ang II. The physiological importance of this mechanism is illustrated by the observation that if renal perfusion was prevented from rising by a servo control device during Ang II infusion, renal sodium reabsorption continued to rise to the point of pulmonary edema (40). Even with continued Ang II infusion, release of the renal clamp led to increased urinary sodium excretion with resolution of pulmonary edema (40). Thus, the net effect of different levels of Ang II on sodium and water excretion depends critically on the balance between the antinatriuretic actions of Ang II and the effect of increased renal perfusion pressure that tends to cause natriuresis.

Most of the known actions of Ang II in the kidney and other organs are mediated by angiotensin receptors of the $\mathrm{AT}_{1}$ subtype coupled to various signal transduction pathways through pertussis toxin-sensitive and pertussis toxin-insensitive $G$ proteins (41). There is evidence that in the proximal tubule Ang II is coupled to a pertussis toxin-sensitive $\mathrm{G}_{\mathrm{i}}$, reducing adenylate cyclase activity and cAMP accumulation. This appears to be the mechanism by which Ang II stimulates proximal tubule bicarbonate absorption (26). In addition, $G$ protein-coupled activation of phospholipase $\mathrm{A}_{2}$ with subsequent metabolization of arachidonic acid by cytochrome P450 epoxygenase to epoxy-eicosa-trienoic acids (EET) apparently mediates the natriuretic effect of Ang II acting on luminal angiotensin receptors (42). In contrast, the activation of phospholipase $\mathrm{C}$, which in most tissues is the major mediator of the biological actions of Ang II, in the kidney appears to be limited to the mediation of Ang II hemodynamic effects (41).

\section{Angiotensin-(1-7) and hydroelectrolyte balance}

One of the major differences between 
Ang II and Ang-(1-7) is the inability of the heptapeptide to stimulate drinking when injected centrally or peripherally $(12,43,44)$. Thus, unlike Ang II, the participation of Ang-(1-7) in fluid homeostasis appears to be restricted to changes in the renal handling of fluid and salt. The role of Ang-(1-7) in the intestinal absorption of water and/or electrolytes has not yet been investigated.

The first description of an effect of Ang(1-7) on water excretion was provided by Santos and Baracho (14) who demonstrated a potent dose-dependent antidiuretic action of Ang-(1-7) in water-loaded rats. This antidiuresis was associated with an increase in water reabsorption and a decrease in creatinine clearance (22). The antidiuresis produced by Ang-(1-7) occurred even when the peptide was administered 60 min after water load, when water diuresis was fully established. As shown in Figure 2, administration of Ang-(1-7) produced a significant decrease in urinary volume $30 \mathrm{~min}$ after its injection $(0.58 \pm 0.30$ vs $1.67 \pm 0.33 \mathrm{ml} / 30 \mathrm{~min}$ in the control group, $\mathrm{P}<0.05)$. Sixty minutes after treatment with Ang-(1-7), a slight decrease in urinary volume was observed, which, however, was not significant when compared with vehicle-treated rats $(0.70 \pm 0.18 v s 1.25$ $\pm 0.51 \mathrm{ml} / 60 \mathrm{~min}$, respectively, $\mathrm{P}>0.05$ ). Similar results were observed in the group treated with avian vasopressin (AVP). Intraperitoneal injection of this peptide produced a significant reduction in water diuresis 30 min after its administration $(0.63 \pm 0.47 v s$ $1.67 \pm 0.33 \mathrm{ml} / 30 \mathrm{~min}$ in vehicle-treated rats, $\mathrm{P}<0.05)$. The antidiuretic effect produced by AVP was also observed 60 min after water load $(0.25 \pm 0.10 v s$ s $1.25 \pm 0.51 \mathrm{ml} / 60 \mathrm{~min}$ in the control group, $\mathrm{P}<0.05$ ). This observation ruled out the possibility that the antidiuretic effect produced by Ang-(1-7) in water-loaded rats was due to the interference with gastrointestinal water reabsorption. The physiological relevance of these data was substantiated by the utilization of the selective Ang(1-7) antagonist, A-779 (11). This compound antagonizes several actions of Ang-(1-7), including its antidiuretic effect $(11,45)$. The acute administration of A-779 in conscious rats produced a diuretic effect $(1.12 \pm 0.32$ $\mathrm{ml} / \mathrm{h}$ vs $0.13 \pm 0.03 \mathrm{ml} / \mathrm{h}$ in vehicle-treated rats, $\mathrm{P}<0.05$ ) which was associated with an increase in creatinine clearance $(1.09 \pm 0.35$ $\mathrm{ml} / \mathrm{min}$ vs $0.34 \pm 0.04 \mathrm{ml} / \mathrm{min}$ in vehicletreated rats, $\mathrm{P}<0.05)$ and a decrease in urinary osmolality $(556 \pm 88 \mathrm{mOsm} / \mathrm{kg} v s 1990$ $\pm 149 \mathrm{mOsm} / \mathrm{kg}$ in vehicle-treated rats, $\mathrm{P}<0.05$ ), as shown in Figure 3. The acute administration of a vasopressin $V_{2}$ receptor antagonist produced a similar diuretic effect (Figure 3). However, the diuresis produced by vasopressin blockade was also associated

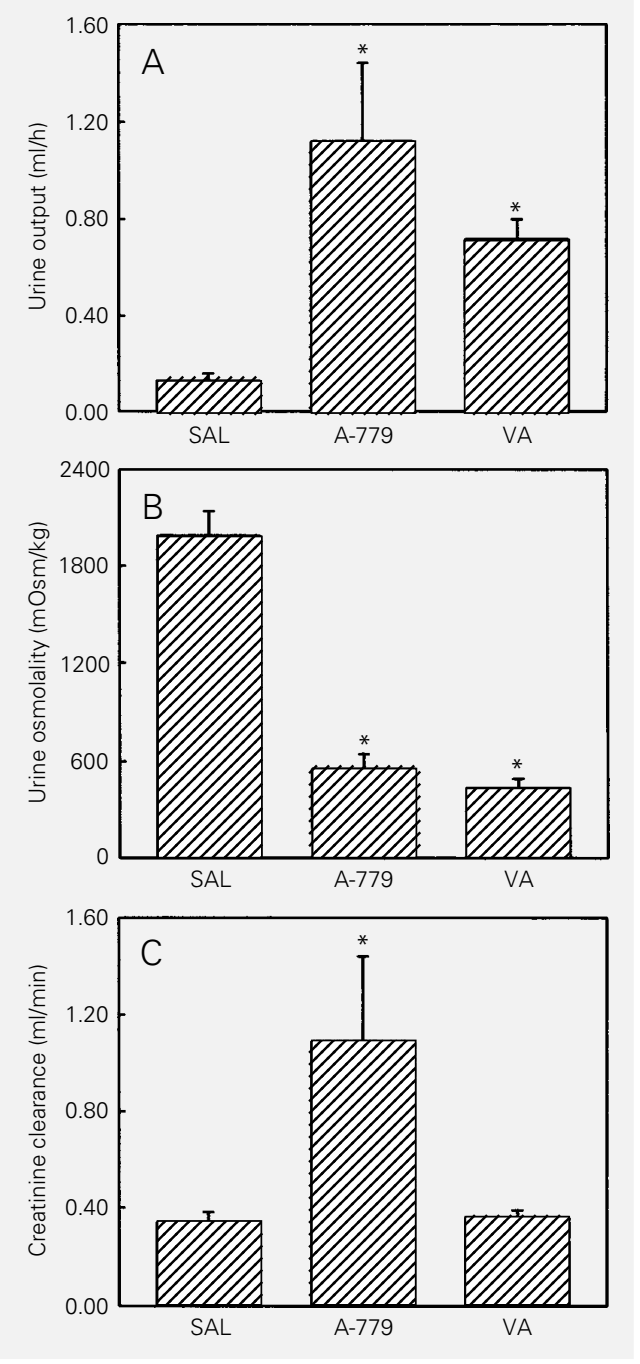

Figure 3 - Effect of D-Ala 7 -angiotensin-(1-7) (A-779) and an AVP$V_{2}$ antagonist on urine output, urine osmolality and creatinine clearance in awake rats. Male Wistar rats (280-320 g) were transferred to metabolic cages with tap water and standard chow. Twenty-four hours later, the animals were treated subcutaneously with A-779 (4.6 $\mathrm{nmol} / 100 \mathrm{~g}$ body weight, $\mathrm{N}=5$ ), a vasopressin $V_{2}$-receptor antagonist (adamantaneacetyl OEt-D-Tyr ${ }^{2}$, Val $^{4}{ }^{4}$, aminobutyryl ${ }^{6}$, Arg ${ }^{8,9}$-vasopressin (VA, 3.2 nmol/100 g body weight, $N=$ $5))$, or vehicle $(0.9 \% \mathrm{NaCl}, \mathrm{SAL}$, $\mathrm{N}=10$ ). Immediately after the treatments, the animals were transferred to metabolic cages and the volume of urine was measured and collected for $6 \mathrm{~h}$. Blood for determination of the effect of A-779 or VA on renal function was obtained under anesthesia immediately after urine collection. The effect of A-779 and $V A$ on basal urinary output (A), urinary osmolality (B) and creatinine clearance $(C)$ is shown. Data are reported as mean \pm SEM. ${ }^{*} P<0.05 \mathrm{com}$ pared to vehicle-treated animals (ANOVA, followed by the Newman-Keuls test). 
with an increase in water excretion, but not with changes in creatinine clearance as shown in Figure 3. These results suggest that, in contrast to vasopressin, endogenous Ang(1-7) influences water reabsorption also acting at the glomerular level. Pawloski-Dahm and Fink (19) also observed an antidiuretic effect in normal rats chronically infused with Ang-(1-7). In contrast, a natriuretic and diuretic effect of Ang-(1-7) was observed in other studies $(16,17)$. Using isolated perfused rat kidneys, Dellipizzi et al. (16) observed a natriuretic effect associated with an increase of urinary volume following infusion of Ang-(1-7). Handa et al. (17) also reported an increase in sodium and water excretion after intrarenal injection of Ang(1-7) in $\mathrm{Na}^{+}$-replete anesthetized male Wistar rats with denervated kidneys. In addition, an inhibitory effect of Ang-(1-7) on $\mathrm{Na}^{+}$transport in cultured renal epithelial cells was previously demonstrated by Andreatta-Van Leyen et al. (18).

Neither the antidiuretic action of Ang-(17) in water-loaded rats (14) nor the natriuretic/diuretic effect observed in anesthetized/ kidney denervated animals (17) was substantiated by infusion of high doses of Ang(1-7) (46) in euvolemic rats. No changes in urinary volume or in urinary osmolality were observed in these experiments. However, chronic infusion of the Ang-(1-7) antagonist A-779 produced sustained diuresis in conscious male Wistar rats (47), suggesting that the possible physiological role of Ang-(1-7) is mainly as an endogenous antidiuretic peptide.

\section{Angiotensin-(1-7) and vasopressin}

Schiavone et al. (5) provided the first demonstration of a biological action of Ang(1-7) by showing that Ang-(1-7) was equipotent to Ang II in releasing vasopressin from hypothalamo-neurohypophyseal explants. These data were substantiated by the observation of immunoreactivity against Ang-(1-
7) in brain areas associated with hydromineral balance, the hypothalamus and neurohypophysis (13). However, other studies did not provide conclusive data regarding the possible central Ang-(1-7)-AVP interaction suggested by these early reports. Mahon et al. (44) reported that intracerebroventricular injections of Ang-(1-7) had no effect on vasopressin release, and induced a pattern of $c$-fos protein expression in the forebrain which is significantly different from that obtained with Ang II injection. For example, Ang-(1-7) did not induce $c$-fos expression in paraventricular or supraoptic nuclei. On the other hand, unlike Ang II, peripheral administration of Ang-(1-7) failed to change plasma AVP levels $(22,46)$. The antidiuretic effect of Ang-(1-7) in water-loaded rats was not blocked by a vasopressin $\mathrm{V}_{2}$ receptor antagonist at doses that abolished the antidiuresis produced by vasopressin, and was not associated with changes in plasma vasopressin levels (22). As mentioned before, a similar finding was previously obtained in normal rats chronically infused with Ang(1-7) in which a dissociation of the antidiuresis and the increase of plasma AVP was observed (19). Benter et al. (46) also reported no changes in plasma levels of vasopressin in Wistar Kyoto or Sprague-Dawley rats during Ang-(1-7) infusion. Interestingly, a significant reduction in plasma vasopressin levels was observed in spontaneously hypertensive rats infused with Ang-(1-7). Taken together, these observations indicate that the release of vasopressin did not contribute to the renal actions of Ang-(1-7). However, the possibility that in situations of chronic osmotic imbalance Ang-(1-7) may contribute to changes in plasma AVP levels cannot be ruled out.

\section{Glomerular actions}

The effects of Ang-(1-7) on the GFR are apparently dependent on the experimental conditions. In water-loaded conscious rats, 
Ang-(1-7) administration significantly reduced creatinine clearance (22). However, in further experiments carried out in our laboratory, no significant changes in the GFR (estimated by inulin clearance, $\mathrm{Cl}_{\text {In }}$ ) were observed in thiopental-anesthetized rats submitted to acute extracellular volume expansion. In these experiments, infusion of Ang(1-7) $\left(30 \mathrm{ng}\right.$ min $^{-1} 100 \mathrm{~g}$ body weight ${ }^{-1}$ ) reduced the $\mathrm{Cl}_{\text {In }}$ from $0.61 \pm 0.1$ to $0.56 \pm$ $0.01 \mathrm{ml} \mathrm{min}^{-1} 100 \mathrm{~g}$ body weight $^{-1}$. Chronic (47) or acute (Figure 3, Ref. 22) administration of the selective Ang-(1-7) antagonist A779 to conscious rats produced a significant increase in creatinine clearance. Conversely, small increases in GFR following Ang-(1-7) infusion were reported in isolated rat kidneys $(16,48)$. The results obtained in our laboratory using anesthetized rats, and by others in isolated rat kidneys suggest that the glomerular actions of Ang-(1-7) are significantly blunted by kidney denervation and anesthesia. In addition, differences in the sensitivity to Ang-(1-7) among rat strains should be considered when interpreting these results (22). The presence of angiotensin receptors with a relatively high affinity for Ang-(1-7) (30 nM) in the mesangium (49) probably accounts for the glomerular effects of the heptapeptide, since there is no evidence for significant changes in renal blood flow produced by Ang-(1-7) (17).

\section{Tubular effects}

Several studies have provided evidence that Ang-(1-7) can influence proximal and distal tubular transport mechanisms. In perfused proximal straight tubules, Garcia and Garvin (20) found that Ang-(1-7) at a concentration of $1 \mathrm{pM}$ increased fluid and bicarbonate absorption. The increase in bicarbonate reabsorption could not be attributed to an increase in the maximum bicarbonate absorption rate or to changes in bicarbonate permeability. Conversely, at a high concentration (10 nM) Ang-(1-7) decreased fluid absorption. On the other hand, using isolated rat proximal tubules, Handa et al. (17) found that Ang-(1-7) induced only a dose-dependent decrease in $\mathrm{O}_{2}$ consumption over a large range of concentrations ( 0.1 to $10 \mathrm{nM})$. Besides other explanations for the apparent divergent results of Handa et al. (17) and Garcia and Garvin (20), including the presence of straight and convolute tubules in Handa's proximal tubule preparation, the extensive handling of the kidney tissue used in the study of Handa et al. (17) to prepare the crude proximal tubule preparation probably accounts for the observed differences.

In accordance with the data obtained by Garcia and Garvin (20) using a high concentration of Ang-(1-7) and those obtained by Handa et al. (17), an inhibitory role of Ang(1-7) in sodium reabsorption was described by Andreatta-Van Leyen et al. (18), using primary cultures of rabbit proximal tubular cells.

The data available about the actions of Ang-(1-7) on the distal nephron are restricted to the inner medullary collecting ducts (IMCD). At a $10 \mathrm{nM}$ concentration Ang-(17) increased water conductivity 4 -fold in the rat IMCD (22). The stimulatory effect of Ang-(1-7) on water permeability in this nephron segment is dose-dependent, can be blocked by A-779 and, interestingly, also by an $\mathrm{AVP}-\mathrm{V}_{2}$ receptor antagonist (Magaldi AJ, personal communication). Regarding this last observation, it would be interesting to explore the involvement of the recently described AVP-angiotensin receptor (50) in the renal effects of Ang-(1-7). In contrast to the dose-related increase of water reabsorption induced by Ang-(1-7) in IMCD (22), in the frog skin the heptapeptide alters osmotic permeability biphasically, increasing it at low concentrations ( $1 \mathrm{nM})$ and decreasing it at higher concentrations (10 nM) (21). Indirect evidence for an action of Ang-(1-7) on the collecting ducts has also been provided by Santos and Baracho (14) and Santos et al. (22). 
Angiotensin-(1-7) and renal prostanoids

There are few data about the possible interaction between Ang-(1-7) and prostanoids in the kidney. A significant prostaglandin-releasing activity of Ang-(1-7) was demonstrated in the vasa deferentia (51) and cultured endothelial cells (7). This prostaglandin-releasing activity of Ang-(1-7) may also be involved in the renal actions of the heptapeptide. We provided in vivo evidence of a possible modulatory effect of prostaglandins on the antidiuresis produced by Ang-(1-7) in water-loaded rats (22). In that study pretreatment with the cyclo-oxygenase inhibitor indomethacin potentiated the antidiuretic effect of Ang-(1-7) (22). In addition, in vitro studies also provided evidence for an interaction between Ang-(1-7) and prostaglandins at the renal tubular level $(18,48)$. Using cultured renal epithelial cells, Andreatta-Van Leyen et al. (18) observed that Ang-(1-7) significantly increased phospholipase $A_{2}$ activity and suggested that this heptapeptide may be involved in the regulation of electrolyte transport in proximal tubular epithelium by phospholipase $\mathrm{A}_{2}$ activation. Hilchey et al. (48), using isolated perfused kidney, reported that Ang-(1-7) selectively stimulated renal $\mathrm{PGI}_{2}$ and suggested that this effect may be related to the natriuresis observed during Ang-(1-7) infusion.

Taken together, these findings suggest that prostaglandins released by Ang-(1-7) from endothelial cells (7) or through activation of phospholipase $\mathrm{A}_{2}$ at the tubular level (18) could modulate the effects of Ang-(1-7) on water and sodium transport.

\section{Angiotensin-(1-7) and angiotensin receptors}

There is growing evidence that the actions of Ang-(1-7) in the kidney or other sites are mediated by specific receptors $(3,10,11$, $17,22,45,52,53)$. In the kidney the antidiuretic action of Ang-(1-7) in water-loaded rats is blocked by the selective Ang-(1-7) antagonist A-779 which shows very low affinity for classical angiotensin II receptors ( $\mathrm{AT}_{1}$ and $\mathrm{AT}_{2}$ subtypes) (22). On the other hand, Garcia and Garvin (20) found that the effects of Ang-(1-7) on fluid and bicarbonate absorption in isolated proximal tubules were blocked by the $\mathrm{AT}_{1}$ receptor antagonist losartan. A similar observation was made by Simões e Silva et al. (54) who noticed the blockade by losartan of the antidiuretic effect of Ang-(1-7) in water-loaded rats. A partial blockade of the effect of Ang-(1-7) on $\mathrm{O}_{2}$ consumption in rat proximal tubules was also observed by Handa et al. (17). We suggest that these findings should be interpreted as evidence that losartan can bind to a subtype of Ang-(1-7) receptors rather than that, under these conditions, Ang-(1-7) acts through $\mathrm{AT}_{1}$ receptors. The main reason for this interpretation is that Ang-(1-7) lacks two of the most classical actions of Ang II mediated by $\mathrm{AT}_{1}$ receptors, i.e., vasoconstriction and induction of drinking. Furthermore, Ang-(1-7) binds poorly to $\mathrm{AT}_{1}$ receptors $(3,11)$. Obviously, other explanations can be proposed, including conformational changes of the $\mathrm{AT}_{1}$ receptors which permit Ang-(1-7) binding to occur. However, these possibilities are less likely than losartan binding to an Ang-(1-7) receptor.

Although further studies are obviously needed to demonstrate the existence of specific Ang-(1-7) receptors, the observations made with the Ang-(1-7) analogue D-Ala ${ }^{7}$ Ang-(1-7) (A-779) in the brain $(10,11,45,55)$ and in the periphery (22) strongly suggest that a non- $\mathrm{AT}_{1}$, non- $\mathrm{AT}_{2}$ receptor mediates the biological actions of Ang-(1-7).

\section{Angiotensin-(1-7) signal transduction}

There are few studies dealing with signal transduction associated with the actions of Ang-(1-7) in the kidney or other organs. Ang-(1-7) was as potent as Ang II in terms of prostaglandin release but did not activate 
phospholipase $\mathrm{C}$ or mobilize intracellular calcium in human astrocytoma cell lines (56). Evidence for the existence of an Ang-(1-7) receptor linked to phospholipase $A_{2}$ was also obtained by Jaiswal et al. $(6,7,57)$ in C6 glioma cells, endothelial cells and human astrocytes. These studies confirmed the original observation of Trachte et al. (51) in isolated rabbit vasa deferentia. Evidence for the participation of a signal transduction pathway for Ang-(1-7) mediated by phospholipase $\mathrm{A}_{2}$ in the kidneys was provided by Andreatta-Van Leyen et al. (18). Indirect evidence for such pathway was obtained by Hilchey et al. (48) and Santos et al. (22) (see above). The observation that the increase in water permeability induced by Ang-(1-7) in IMCD is blocked by the protein-kinase A inhibitor H8 (Magaldi AJ, personal communication) suggests that a signal transduction pathway mediated by adenylate cyclase also contributes to the effects of Ang-(1-7) in the kidney. There is an inverse relationship between cAMP and $\mathrm{Na}^{+}$and bicarbonate reabsorption probably related to changes in the phosphorylation of the $\mathrm{Na}^{+}-\mathrm{H}^{+}$exchanger on the luminal cell surface (41). Thus, an attractive hypothesis is that Ang-(1-7) stimulates adenylate cyclase which may explain both its natriuretic action in the proximal tubule $(16,17)$ and its effect on water permeability in the collecting ducts (22), reducing plasma osmolarity.

In summary, Ang II and Ang-(1-7) can be formed locally (58) and influence several aspects of kidney function. The novel activities described for Ang-(1-7) in this organ suggest that this angiotensin peptide may be responsible for an important subset of angiotensinergic effects influencing the hydroelectrolyte balance.

\section{References}

1. Ferrario $\mathrm{CM}$, Barnes $\mathrm{KL}$, Block $\mathrm{CH}$, Brosnihan KB, Diz DI, Khosla MC \& Santos RAS (1990). Pathways of angiotensin formation and function in the brain. Hypertension, 15: I.13-I.19.

2. Goodfriend TL (1991). The angiotensins A family that grows from within. Hypertension, 17: 139-140.

3. Santos RAS \& Campagnole-Santos MJ (1994). Central and peripheral actions of angiotensin-(1-7). Brazilian Journal of Medical and Biological Research, 27: 1033-1047.

4. Santos RAS, Brosnihan KB, Chappell MC, Pesquero JL, Chernicky CL, Greene LJ \& Ferrario CM (1988). Converting enzyme activity and angiotensin metabolism in the dog brainstem. Hypertension, 11: 153157.

5. Schiavone MT, Santos RAS, Brosnihan KB, Khosla MC \& Ferrario CM (1988). Release of vasopressin from the rat hypothalamo-neurohypophysial system by angiotensin-(1-7) heptapeptide. Proceedings of the National Academy of Sciences, USA, 85: 4095-4098.
6. Jaiswal N, Diz DI, Tallant EA, Khosla MC \& Ferrario CM (1991). Characterization of angiotensin receptors mediating prostaglandin synthesis in CG glioma cells. American Journal of Physiology, 260: R1000-R1006.

7. Jaiswal N, Diz DI, Chappell MC, Khosla MC \& Ferrario CM (1992). Stimulation of endothelial cell prostaglandin production by angiotensin peptides. Characterization of receptors. Hypertension, 19 (Suppl II): 49-55.

8. Campagnole-Santos MJ, Diz DI, Santos RAS, Khosla MC, Brosnihan KB \& Ferrario CM (1989). Cardiovascular effects of angiotensin (1-7) microinjected into the dorsal medulla of rats. American Journal of Physiology, 257: H324-H329.

9. Silva LCS, Fontes MAP, CampagnoleSantos MJ, Khosla MC, Campos Jr RR, Guertzenstein PG \& Santos RAS (1993). Cardiovascular effects produced by microinjection of angiotensin-(1-7) on vasopressor and vasodepressor sites of the ventrolateral medulla. Brain Research, 613: 321-325.
10. Fontes MAP, Silva LCS, CampagnoleSantos MJ, Khosla MC, Guertzenstein PG \& Santos RAS (1994). Evidence that angiotensin-(1-7) plays a role in the central control of blood pressure at the ventrolateral medulla acting through specific receptors. Brain Research, 665: 175-180.

11. Santos RAS, Campagnole-Santos MJ, Baracho NCV, Fontes MAP, Silva LCS, Neves LAA, Oliveira DR, Caligiorne SM, Rodrigues ARV, Gropen Jr C, Carvalho WS, Simões e Silva AC \& Khosla MC (1994). Characterization of a new angiotensin antagonist selective for angiotensin-(1-7): Evidence that the actions of angiotensin-(1-7) are mediated by specific angiotensin receptors. Brain Research Bulletin, 35: 293-298.

12. Campagnole-Santos MJ, Heringer SB Batista EN, Khosla MC \& Santos RAS (1992). Differential baroreceptor reflex modulation by centrally infused angiotensin peptides. American Journal of Physiology, 263: R89-R94.

13. Block $\mathrm{CH}$, Santos RAS, Brosnihan KB \& Ferrario CM (1988). Immunocytochemical localization of angiotensin (1-7) in the rat forebrain. Peptides, 9: 1395-1401. 
14. Santos RAS \& Baracho NCV (1992). Angiotensin-(1-7) is a potent antidiuretic peptide in rats. Brazilian Journal of Medical and Biological Research, 25: 651-654.

15. Botelho LM, Block $\mathrm{CH}$, Khosla MC \& Santos RAS (1994). Plasma angiotensin(1-7) levels are increased by water deprivation, salt load and hemorrhage. Peptides, 15: 723-729.

16. Dellipizzi A, Hilchley SD, McGiff JC \& BellQuilley CP (1994). Natriuretic action of angiotensin-(1-7). British Journal of Pharmacology, 111: 1-4.

17. Handa RK, Ferrario CM \& Strandhoy JW (1996). Renal actions of angiotensin-(1-7): in vivo and in vitro studies. American Journal of Physiology, 270 (Renal Fluid and Electrolyte Physiology): F141-F147.

18. Andreatta-Van Leyen S, Romero MF, Khosla MC \& Douglas JG (1993). Modulation of phospholipase $A_{2}$ activity and sodium transport by angiotensin-(1-7). Kidney International, 44: 932-936.

19. Pawloski-Dahm C \& Fink GD (1992). Chronic intravenous infusion of angiotensin-(1-7) produces increases in circulating vasopressin but not arterial pressure. Hypertension, 20: 69 (Abstract).

20. Garcia NH \& Garvin JL (1994). Angiotensin-(1-7) has a biphasic effect on fluid absorption in the proximal straight tubule. Journal of the American Society of Nephrology, 5: 1133-1138.

21. Fariña MDD, Santos RAS \& Lopes MJ (1995). Angiotensin-(1-7) has a biphasic effect on frog (Rana catesbeiana) skin osmotic permeability. Hypertension, 25: 1409 (Abstract).

22. Santos RAS, Simões e Silva AC, Khosla MC, Magaldi AJ, Cesar KR, Passaglio KT \& Baracho NCV (1996). Evidence for a physiological role of angiotensin-(1-7) in the control of hydroelectrolyte balance. Hypertension, 27: 875-884.

23. Hall JE (1986). Control of sodium excretion by angiotensin II: intrarenal mechanisms and blood pressure regulation. American Journal of Physiology, 250: R960-R972.

24. Hall JE (1991). The renin angiotensin system: Renal actions and blood pressure regulation. Comprehensive Therapy, 17: 8-17.

25. Olsen ME, Hall JE, Montani JP, Guyton AC, Langford HG \& Cornell JE (1985). Mechanisms of angiotensin II natriuresis and antinatriuresis. American Journal of Physiology, 249: F299-F307.
26. Ichikawa I \& Harris RC (1991). Angiotensin actions in the kidney. Renewed insight into the old hormone. Kidney International, 40: 583-596.

27. Pelayo JC (1988). Renal adrenergic effector mechanisms: Glomerular sites for prostaglandin interaction. American Journal of Physiology, 254 (Renal Fluid and Electrolyte Physiology, 23): F184-F190.

28. Fredlund P, Saltman S \& Catt P (1975). Aldosterone production by isolated adrenal glomerulosa cells: Stimulation by physiological concentrations of angiotensin II. Endocrinology, 97: 1577-1582.

29. Myers ED, Dean WM \& Brenner BM (1975). Effects of norepinephrine and angiotensin II on the determinants of glomerular ultrafiltration and proximal tubule fluid reabsorption in the rat. Circulation Research, 37: 101-109.

30. Blantz RC, Konnen KS \& Tucker BJ (1976). Angiontensin II effects upon the glomerular microcirculation and ultrafiltration coefficient of the rat. Journal of Clinical Investigation, 57: 419-424.

31. Brenner BM, Troy JL \& Daugharty TN (1971). The dynamics of glomerular ultrafiltration in the rat. Journal of Clinical Investigation, 50: 1776-1782.

32. Schor N, Ichikawa I \& Brenner BM (1981). Mechanisms of action of various hormones and vasoactive substances on glomerular ultrafiltration in the rat. Kidney International, 20: 442-450

33. Ichikawa I \& Brenner BM (1980). Importance of efferent arteriolar vascular tone in regulation of proximal tubule fluid and glomerulotubular balance in the rat. Journal of Clinical Investigation, 65: 11921199.

34. Navar LG \& Rocivall L (1984). Contribution of the renin angiotensin system to the control of intrarenal hemodynamics. Kidney International, 25: 857-863.

35. Brezis M, Greenfeld Z, Shina A \& Rosen S (1990). Angiotensin II augments medullary hypoxia and predisposes to acute renal failure. European Journal of Clinical Investigation, 20: 199-207.

36. Arendshorst WJ \& Finn WF (1977). Renal hemodynamics before and during inhibition of angiotensin II. American Journal of Physiology, 233: F290-F297.

37. Harris PJ \& Navar LG (1985). Tubular transport responses to angiotensin. American Journal of Physiology, 248: F621-F630.
38. Liu FY \& Cogan MG (1988). Angiotensin II stimulation of hydrogen ion secretion in rat early proximal tubule. Journal of Clinical Investigation, 82: 601-606.

39. Barreto-Chaves MLM \& Mello-Aires M (1996). Angiotensin II stimulates the $\mathrm{Na}^{+}$$\mathrm{H}^{+}$exchanger and the $\mathrm{H}^{+}$-ATPase on cortical distal tubule via $\mathrm{AT}_{1}$ receptors. American Journal of Physiology (in press).

40. Hall JE, Granger JP, Hester RL, Coleman TG, Smith MJ \& Cross RB (1984). Mechanisms of escape from sodium retention during angiotensin II hypertension. American Journal of Physiology, 246: F627F634.

41. Douglas JG \& Hopfer U (1994). Novel aspects of angiotensin receptors and signal transduction in the kidney. Annual Review of Physiology, 56: 649-669.

42. Romero MF, Hopfer U, Madhun ZT, Zhou J \& Douglas JG (1991). Angiotensin II actions in the rabbit proximal tubule. Angiotensin II mediated signaling mechanisms and electrolyte transport in the rabbit proximal tubule. Renal Physiology and Biochemistry, 14: 199-207.

43. Fitzsimons JT (1971). The effect on drinking of peptide precursor and of short chain peptide fragments of angiotensin II injected into the rat diencephalon. Journal of Physiology, 214: 295-303.

44. Mahon JM, Allen M, Herbert J \& Fitzsimons JT (1995). The association of thirst, sodium appetite and vasopressin release with c-fos expression in the forebrain of the rat after intracerebroventricular injection of angiotensin II, angiotensin(1-7) or carbachol. Neuroscience, 69: 199208.

45. Ambühl P, Felix D \& Khosla MC (1994). [7D-Ala]-Angiotensin-(1-7): Selective antagonism of angiotensin-(1-7) in the rat paraventricular nucleus. Brain Research Bulletin, 35: 289-291.

46. Benter IF, Ferrario CM, Morris M \& Diz DI (1995). Antihypertensive actions of angiotensin-(1-7) in spontaneously hypertensive rats. American Journal of Physiology, 269 (Heart and Circulatory Physiology, 38): $\mathrm{H} 313-\mathrm{H} 319$.

47. Simōes e Silva AC, Baracho NCV, Khosla MC \& Santos RAS (1995). Diuresis and natriuresis produced by long-term administration of a selective angiotensin-(1-7) antagonist in rats. Hypertension, 25: 56 (Abstract). 
48. Hilchey SD, Caroline P \& Bell-Quilley CP (1995). Association between the natriuretic action of angiotensin-(1-7) and selective stimulation of renal prostaglandin $\mathrm{I}_{2}$ release. Hypertension, 25: 1238-1244.

49. Ernsberger $P$, Zhou J, Damon TH \& Douglas JG (1992). Angiotensin II receptor subtypes in cultured rat renal mesangial cells. American Journal of Physiology, 263: F411-F416.

50. Ruiz-Opazo N, Akimoto K \& Herrera VLM (1995). Identification of a novel dual angiotensin II/vasopressin receptor on the basis of molecular recognition theory. $\mathrm{Na}$ ture Medicine, 1: 1074-1081.

51. Trachte GJ, Meixner K, Ferrario CM \& Khosla MC (1990). Prostaglandin production in response to angiotensin-(1-7) in rabbit isolated vasa deferentia. Prostaglandins, 39: 385-389.
52. Brosnihan KB, Li P \& Ferrario CM (1996). Angiotensin-(1-7) dilates canine coronary arteries through kinins and nitric oxide. Hypertension, 27: 523-528.

53. Freeman EJ, Chisolm GM, Ferrario CM \& Tallant EA (1996). Angiotensin-(1-7) inhibits vascular smooth muscle cell growth. Hypertension, 28: 104-108.

54. Simões e Silva AC, Baracho NCV \& Santos RAS (1993). Contribuição dos receptores angiotensinérgicos $A T_{1}$ e $A T_{2}$ para o efeito antidiurético da Angiotensina-(1-7) em ratos. Proceedings Sociedade Brasileira de Hipertensão, 42 (Abstract).

55. Oliveira DR, Santos RAS, Santos GFP, Khosla MC \& Campagnole-Santos MJ (1996). Changes in the baroreflex control of heart rate produced by central infusion of selective angiotensin antagonists in hypertensive rats. Hypertension, 27: 12841290.
56. Tallant EA, Jaiswal N, Diz DI \& Ferrario CM (1991). Human astrocytes contain two distinct angiotensin receptor subtypes. Hypertension, 18: 32-39.

57. Jaiswal N, Tallant EA, Diz DI, Khosla MC \& Ferrario CM (1991). Subtype 2 angiotensin receptors mediate prostaglandin synthesis in human astrocytes. Hypertension, 17: 1115-1120.

58. Erdös EG \& Skidgel RA (1990). Renal metabolism of angiotensin I and II. Kidney International, 38: S24-S27. 